\title{
Lutzomyia longipalpis in Clorinda, Formosa province, an area of potential visceral leishmaniasis transmission in Argentina
}

\author{
O scar D Salomón/ ${ }^{+}$, Pablo W 0 rellano*
}

\begin{abstract}
Centro Nacional de Diagnóstico e Investigación en Endemo-Epidemias, CeNDIE-ANLIS, Ministerio de Salud y Ambiente de la Nación, Av. Paseo Colón 568, 1263, Buenos Aires, Argentina *Programa de Residencia en Epidemiología de Campo, Ministerio de Salud y Ambiente de la Nación, Buenos Aires, Argentina
\end{abstract}

Phlebotomine captures were performed during 2004 in Clorinda, Argentina. Clorinda is located across the branches of the Paraguay river in front of Asunción city, Paraguay. Reports of canine and human visceral leishmaniasis in Asunción have been increasing since 1997, however neither leishmaniasis cases nor sand flies were ever recorded from Clorinda. Light traps were located in migration paths (bridges, port), and peridomestic environments of Clorinda and surrounding localities. Lutzomyia longipalpis was found in Clorinda and Puerto Pilcomayo, first report in a potential visceral leishmaniasis transmission area for Argentina. Active surveillance is required immediately in the localities involved and the surrounding area.

Key words: Lutzomyia longipalpis - visceral leishmaniasis - Argentina

Fourteen cases of autochtonous leishmaniasis with visceral involvement were recorded in Argentina from 1925 to 1989 scattered in time and space (Salomón et al. 2001). Since then two cases of visceral leishmaniasis (VL) with parasite characterization were reported, but one was imported from Brazil (Nocito et al. 2002), and the other from Spain (Martín-Sánchez et al. 2004). Further, Lutzomyia longipalpis (Lutz \& Neiva, 1912), the known vector of VL in the New World (Le Pont \& Desjeux 1985, Lainson \& Rangel 2003) was not found in the captures performed in the six provinces that reported the 14 cases mentioned above (Salomón 2003). In Misiones province scarce individuals of $\mathrm{Lu}$. longipalpis were captured in 1951 and again in 2000 in two places close each other, but no cases of VL have been ever reported there (Salomón et al. 2001). On the other hand, VL canine seroprevalence in Asunción area, Paraguay, ranged from 3.1 to $11.8 \%$ between 1997 and 1999 (Canese 2000), while human VL reported cases from the same area rose from 9 in 2003 to 41 in 2004 (Canese A, pers. commun.). Clorinda city ( $25^{\circ} 17^{\prime} \mathrm{S}, 5^{\circ} 43^{\prime} \mathrm{W}, 47,000$ inhabitants), in Formosa province, is located in front of Asunción City on the Pilcomayo-Paraguay river international border. Therefore, phlebotomine sandflies captures were performed during 2004 in Clorinda in order to assess the presence of Lu. longipalpis and the risk of VL transmission.

Phlebotomine captures were performed with minilight traps CDC like overnight in Clorinda city, Puerto Pilcomayo, Laguna Blanca-Parque Pilcomayo $(60 \mathrm{~km}$ west

+Corresponding author. E-mail: danielsalomon@ hotmail.com Received 15 February 2005

Accepted 11 July 2005 of Clorinda), "Km 1254" and "Km 1264" (60 and $50 \mathrm{~km}$ south of Clorinda respectivelly). Eleven sites were sampled between 7 and 11 June 2004, and 18 sites between 16-21 December 2004, at least two nights each site in both periods. The capture sites were selected within peridomestic habitats with close vegetation, animal dwellings and/or proximity to the border with Paraguay. The phlebotomine were cleared, mounted and identified as already published (Salomón et al. 2002)

Seven individuals (4 males, 3 females) of Lu. longipalpis were captured in peridomestic pig pens of Puerto Pilcomayo ("Km 9" and "Km 11 1/2"). Besides, 3 males of Lu. longipalpis were collected in Clorinda peridomiciles (Libertad street $30 \mathrm{~m}$ from the river and Porteño Norte neighbourhood). One male of Lu. longipalpis was trapped in June, the remainder sand flies were caught in December. Despite the low densities found, this is the first report of a competent vector of VL in Argentina close to a current VL focus, and Formosa the second province ever reported with $L u$. longipalpis in the country.

Lu. cortelezzii (12 individuals), Lu. shannoni (1), and Lu. neivai (4) were also found in Clorinda and Puerto Pilcomayo capture sites, but no sand flies were collected in the surrounding southern or western villages. Lu. neivai is the prevalent species in tegumentary leishmaniasis foci of Formosa province (Salomón et al. 2002).

In conclusion, there is a potential risk of VL transmission in Clorinda due to: i) the presence of Lu. longipalpis in Clorinda close to populated areas, ii) the reports of VL from the 'Great Asunción' in Paraguay, and iii) the fluent movement of individuals, bought and stray dogs along the border. Thus, an active surveillance system is required immediately in the area in order to improve the local capacities on detection and diagnose both human and canine leishmaniasis. The transit of stray dogs in the frontier should be controlled as in any other dog related 
zoonotic scenario. Finally with the aim to evaluate changes in the space-time distribution of the risk a regular monitoring of phlebotomine at strategic places would be performed.

\section{ACKNOWLEDGEMENTS}

To Ministerio de Salud y Ambiente de la Nación, Ministerio de Desarrollo Humano de la Provincia de Formosa, and Fundación Mundo Sano for providing valuable cooperation, field facilities and technical assistance.

\section{REFERENCES}

Canese A 2000. Leishmaniosis visceral canina en el area metropolitana de la "Gran Asunción", Paraguay 2000. Medicina (Buenos Aires) 60 (Supl. III): 65.

Lainson R, Rangel EF 2003. Lutzomyia longipalpis e a ecoepidemiologia da leishmaniose visceral americana (LVA) no Brasil. In EF Rangel, R Lainson (eds), Flebotomíneos do Brasil, Fiocruz, Rio de Janeiro, p. 311-336.

Le Pont F, Desjeux P 1985. Leishmaniasis in Bolivia. I. Lutzomyia longipalpis (Lutz \& Neiva, 1912) as the vector of visceral leishmaniasis in Los Yungas. Trans $R$ Soc Trop
Med Hyg 79: 227-231.

Martín-Sánchez J, Navarro-Mari JM, Pasquau-Liaño J, Salomón OD, Morillas-Márquez F 2004. Visceral leishmaniasis caused by Leishmania infantum in a Spanish patient in Argentina: what is the origin of the infection? Case Report. BMC Infectious Diseases 4: 20.

Nocito I, Serra E, Montero A 2002. Visceral involvement due to Leishmania mexicana in a patient with acquired immunodeficiency syndrome. Am J Med 113: 260-262.

Salomón OD 2003. Phlebotominae. In A González, C Villalobos, MA Ranaletta (eds), Ectoparasitosis Humanas, Ediciones Científicas Americanas, La Plata, p. 121-144.

Salomón OD, Rossi G, Sosa Estani S, Spinelli G 2001. Presencia de Lutzomyia longipalpis y situación de la leishmaniosis visceral en Argentina. Medicina (Buenos Aires) 61: 174178.

Salomón OD, Sosa Estani S, Drí L, Donnet M, Galarza R, Recalde H, Tijera A 2002. Leishmaniosis tegumentaria en Las Lomitas, provincia de Formosa, Argentina, 1992-2001. Medicina (Buenos Aires) 62: 562-568. 